\title{
WEIGHT OPTIMIZATION OF FIX JAW OF REAR VICE OF HORIZONTAL BAND SAW MACHINE USING TOPOLOGY OPTIMIZATION
}

\author{
Prashant H. Patil ${ }^{1}$, Suresh S. Patil ${ }^{2}$ \\ ${ }^{1}$ Padmabhooshan vasantraodada Patil Institute of Technology, Budhgaon, 416034. India \\ ${ }^{2}$ Padmabhooshan vasantraodada Patil Institute of Technology, Budhgaon, 416034. India
}

\begin{abstract}
Horizontal band saw machine is an important machine tool in mechanical workshop. This paper is about Weight reduction of fix jaw of rear vice. Rear vice used for clamping work piece during cutting operation. It has two jaws Fix jaw and movable jaw. Movable jaw attached to hydraulic cylinder which applies force to hold work piece between these two jaw. Reduce weight of components help to minimize load on environmental resources. This efforts for reduction of weight by using topology optimization. fix jaws has been modeled using solid works First conducted analysis on existing jaws with calculating the forces acting on jaws in order to find out Max. Displacement and stress induced. These analyses were carried using Altair Hyperworks and solver used is optistuct. Again conducted topology optimization with applying manufacturing constrain like minimum member size and single type draw direction. Again prepare cad model based on topology result and carried analysis on optimized model. from the analyzed results, Displacement and stress are lower than existing model. From result it was found that current design is safe also save material and cost of component, Finally we reduced total weight by $12 \%$ of current fix jaw model. Topology optimization analysis is carried out in Hyperworks which yielded in weight optimized.
\end{abstract}

Keywords: Horizontal band saw machine, rear vice fix jaw, Hyper works, Optistruct, Topology optimization

\section{INTRODUCTION}

Sawing machine is an important machine tool of mechanical workshop. A sawing machine is a machine tool designed to Cut off bar stock, tubing, pipe, or any metal stock within its Capacity, or to cut sheet stock to desired contours. The sawing Machine functions by bringing a saw blade containing cutting. Teeth in contact with the work piece to be cut, and drawing the cutting teeth through the work piece. The sawing machine is much faster and easier than hand sawing. Sawing machine has two types:

1) Power hack saw

2) Band saw machine.[8]

Where power hack saw machine uses a reciprocating cutting Action, while band saw uses a continuous band blade for SPM TOOLS, Ichalkaranji is a company of FIE GROUP. This company is leading in manufacturing of Horizontal band saw machine. But due to increase in raw Material cost, processing cost, labour cost causes to increase of total machine cost. Hence Company focusing on to reduce manufacturing cost to maintain good sale in market. So in this project work to selected fix jaw of rear vice for weight optimization of model SPM FCAF 245 by using topology optimization method.[6]

Rear vice used for clamping work piece during cutting operation. Rear vice has two jaws one is fixed jaw and another is movable jaw. Moving jaw attached to hydraulic cylinder. Hydraulic cylinder operated by a hydraulic power pack. Pressure dial gauge shows how much Pressure applying on hydraulic cylinder.[6]

Topology Optimization is defined as finding out the best possible material distribution in selected design space with considering the given sets of objective and design constraints. For solving any topology optimization problem have to specify parameters that is Design Variables, responses, Design objective and design constraints also consideration of manufacturing constraints.

Hence in order to accomplish the objective of weight reduction over existing design, Finite Element Analysis method is used. Since from last decade a powerful FEA packages have proven good to analysis. Hence we are going to use finite element analysis software for weight optimization. In which Hypermesh is pre-processor. Optistruct is solver which now days much famous in industry and Hyperview is Post-processor.

After will do FEA analysis of optimized model and check stress, displacement of optimized model do not to exceed magnitude of initial model.[1]

Finally we will manufacture casting of optimized design and applying same load on this casting on universal testing machine (UTM) or horizontal band saw machine If jaw (optimized) sustain these load without failure then optimized design validate. 
This paper deals with 3D modeling of fix jaws. Calculation of force, Analysis, optimization, getting IGES model from optistuct (OSsmooth) and Make appropriate change in that model for manufacturing point of view and cross-check value of displacement within range(lower than Initial model ) finally manufacturing casting validate on universal testing machine or machine.

\section{PROBLEM DEFINITION}

In which fix jaw of Rear vice is taking for project work. Rear vice jaw has two jaws one is fixed another is movable. Hydraulic cylinder attached to movable jaw which applies force to jaw to clamp the workpiece. fix jaw's weight is 12.1 $\mathrm{kg}$. fix are made of ductile iron. Inner diameter of hydraulic cylinder is $80.125 \mathrm{~mm}$, while max. pressure of hydraulic oil on cylinder is $22 \mathrm{~kg} / \mathrm{cm} 2$.Maximum load applying on jaws is $10884 \mathrm{~N}$

Objective is to optimize the structural design of fix jaw of rear vice in order to reduce the material cost by reducing weight of Existing fix jaw without reduction in load bearing capacity. [6]

\subsection{Objective}

The key objective of this effort is to carry out static analysis of fix jaw of rear vice and also perform topology optimization for achieving weight reduction.

- Determinations of the forces acting on fix jaw of rear vice during working conditions.

- Solid modeling of the fix jaw of rear vice.

- Determination of displacement and max. disp. Node number.

- Determination of Von mises stress.

-Topology optimization setup with minimum member Size $(8 \mathrm{~mm})$ and single type draw direction.

- Prepare pattern of optimized model

- Manufacture casting

- Take experimental test on optimized model.

\section{METHODOLOGY}

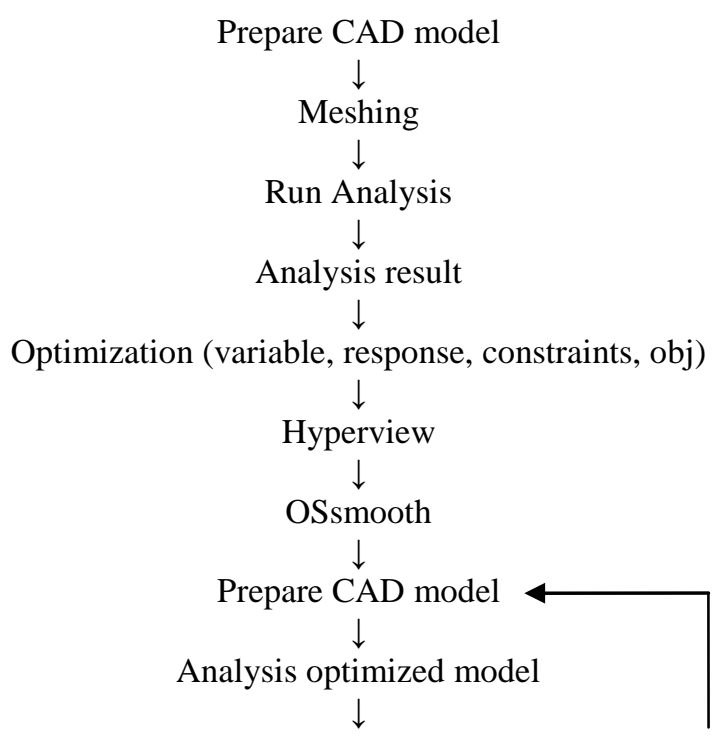

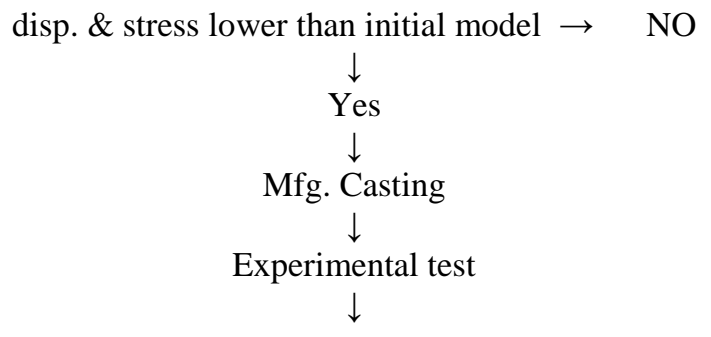

Fig 1 Work flow diagram

In above diagram show that way of project work.[7] In order to proceed with this study various forces acting on Jaw were calculated. CAD model of fix jaw designed in solid works was imported in Hypermesh for geometric cleanup and meshing. Meshed model of fix jaw consist of of 44053 nodes and 202579 elements all are 3D Tetramesh (volumemesh).Tetra elements give enhanced result as compared to other types of elements, therefore the elements used in this analysis is tetra elements.

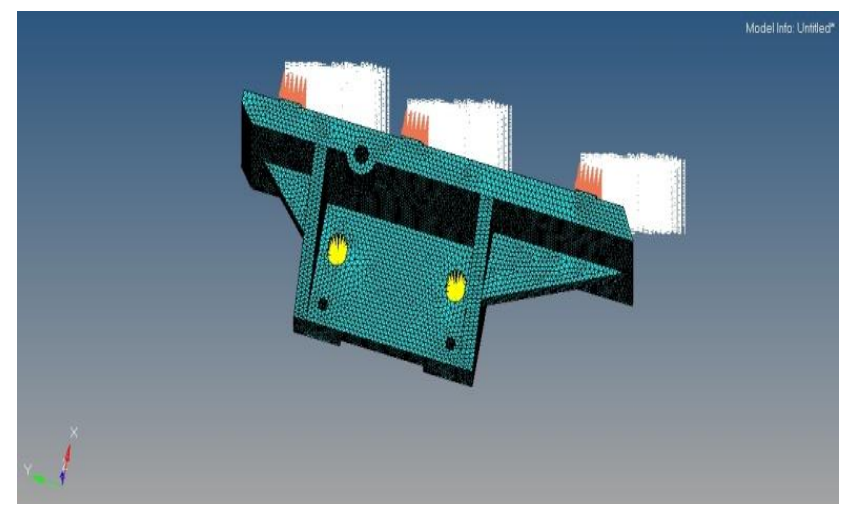

Fig 2 Fix jaw with meshing, loading and boundry Condition

Ductile iron material was used for fix jaw. Calculated forces and boundary conditions were applied on meshed model in Hypermesh as shown in figure 2 .

Static analysis was performed by using optistuct. Viewed Result in Hyperview . All specification, material property And result shown in table1

\subsection{Design Parameters}

\section{1) Forces Acting on Jaws}

Rear vice jaw has two jaws one is fixed another is movable. Hydraulic cylinder attached to movable jaw which applies force to jaw to clamp the work piece. Inner diameter of hydraulic cylinder is $80.125 \mathrm{~mm}$, while maximum pressure of hydraulic oil on cylinder is $22 \mathrm{~kg} / \mathrm{cm} 2$.here we calculate total force applying on fix jaw. [6]

$$
\begin{aligned}
& \mathrm{P}=\mathrm{F} / \mathrm{A} \\
& \mathrm{F}=\mathrm{P} * \mathrm{~A}
\end{aligned}
$$

$\mathrm{F}=22 *\left(3.142 *(4.00625)^{2}\right)=1109.44 \mathrm{~kg}$.

$\mathrm{F}=1109.44 * 9.81=10884 \mathrm{~N}$ 
Maximum load applying on fix jaws is $10884 \mathrm{~N}$.

Considering factor of safety (F.S.) 1.5 then

$$
\mathrm{F}=10884 * 1.5=16326 \mathrm{~N}
$$

Table 1 Material properties and specification of jaws

\begin{tabular}{|l|l|l|}
\hline $\begin{array}{l}\text { paramet } \\
\text { er }\end{array}$ & Description & $\begin{array}{l}\text { fix } \\
\text { jaw }\end{array}$ \\
\hline E & Young's Modulus ( Mpa) & 170000 \\
\hline NU & Poisson's Ratio & 0.275 \\
\hline RHO & Density (kg/m3) & 7100 \\
\hline F & Force(N) factor of safety 1.5 & 16326 \\
\hline M & Wt.of jaw before optimization & $12.1 \mathrm{~kg}$ \\
\hline
\end{tabular}

\section{RESULTS AND DISCUSSIONS}

\subsection{Static Analysis}

Static analysis was performed by using optistuct solver. From figure3, it is observed that the maximum displacement Developed is $0.116 \mathrm{~mm}$ for fix jaw. Stress developed is 97.82 $\mathrm{N} / \mathrm{mm}^{2}$. Which is lower than the Yield strength. Hence, design is safe that is the values of maximum stresses are acceptable as compared to yield strength so design constraints For Optimized fix jaw is to maintain displacement value lower than $0.116 \mathrm{~mm}$.

Table 2: Analyzed results for fix materials

\begin{tabular}{|l|l|}
\hline Description & Fix jaw \\
\hline Max displacement in mm & 0.116 at node \\
& 7888 \\
\hline Von Mises stress $\left(\mathrm{N} / \mathrm{mm}^{2}\right)$ & 97.82 \\
\hline
\end{tabular}

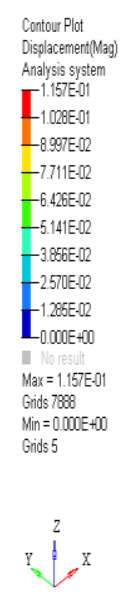

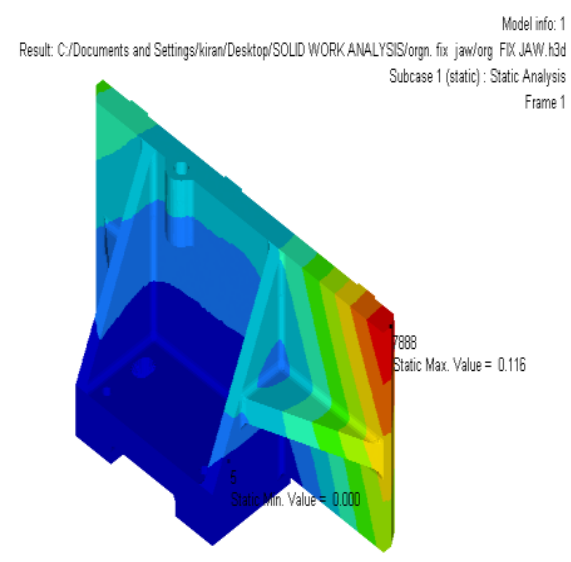

Fig 3 Max Displacement of fix jaw

\subsection{Topology Optimization}

Topology Optimization technique gives an optimum material distribution Within given design space. [7] The design space defined using solid elements. The topology optimization set up in which first is design variable selected as solid and setting up two manufacturing constraints 1. Minimum member size control $(8 \mathrm{~mm})$ 2. Draw direction type
(single).Design response was volume Fraction, weighted comp., displacement. Optimization design constraints were volfrac for that upper bound 0.030. Displacement constraint was upper bound $0.116 \mathrm{~mm}$ for fix jaw.

Finally design objective was Minimum weight compliance. Run optimization by using optistuc Solver. Finally viewed result in hyper view.
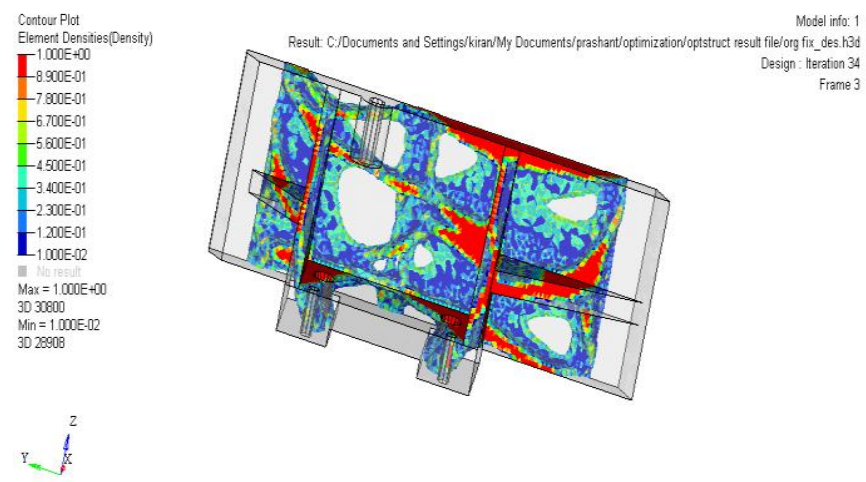

Fig 4 Hyper view element densities of fix jaw

Figure 4 shows element density for fix jaw. Optistruct identifies material distribution pattern throughout jaws and remove material from that region in successive iterations based upon set of objectives and constraints. This material removal is given by varying density of each element from 0 to 1 . After number of iterations, when solution converges the density pattern of component a region with lower density indicate that it can be removed without hampering safety of component. So by removing the material from these design space of component objective of reducing weight of component will be fulfilled with all design constraints.

A conceptual design can be imported in a CAD system using An iso-surface generated with OSSmooth, which is part of OptiStruct. This IGES model imported in solid works makes changes as per manufacturing aspect. Figure 5 Shows CAD model of fix jaws resp.

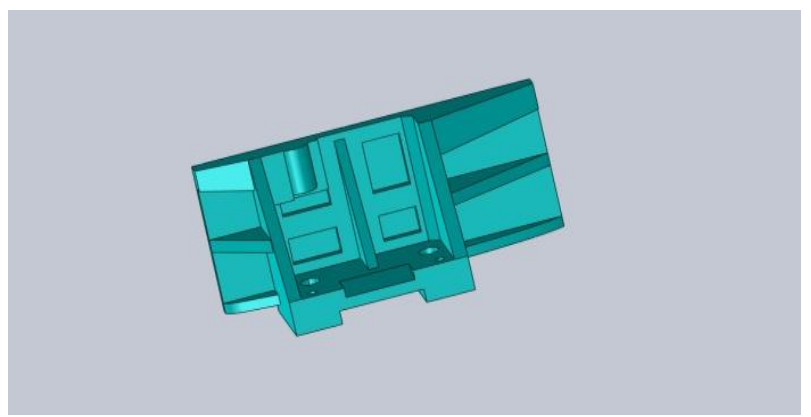

Fig 5 CAD model of optimized fix jaw

Again conduct analysis on newly optimized fix jaw model. Setup all meshing, boundary and loading condition. Cross Check that displacement and stress of optimized model do not exceed value Initial model. Figure 6. Shows displacement result of optimized fix jaw. Displacement of optimized fix jaw is $0.109 \mathrm{~mm}(<0.116 \mathrm{~mm}$ of initial model $)$. 


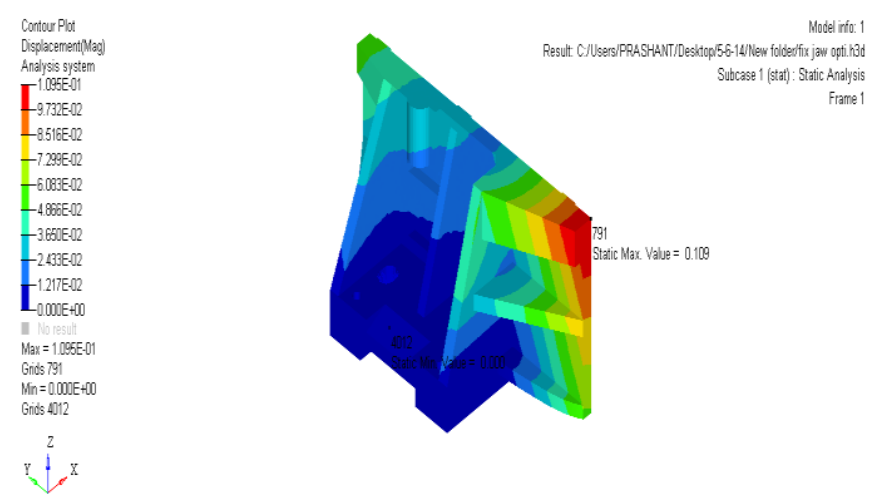

Fig 6 Disp. of optimized fix jaw 0.109mm (0.116)

Table 3: Analyzed results for fix materials

\begin{tabular}{|l|l|l|}
\hline parameter & $\begin{array}{l}\text { fix jaw before } \\
\text { optimized }\end{array}$ & $\begin{array}{l}\text { fix jaw after } \\
\text { optimized }\end{array}$ \\
\hline $\begin{array}{l}\text { Max. } \\
\text { Displacement( } \\
\text { mm })\end{array}$ & 0.116 & 0.109 \\
\hline $\begin{array}{l}\text { Max. Stress } \\
\left(\mathrm{N} / \mathrm{mm}^{2}\right)\end{array}$ & 97.82 & 74.78 \\
\hline $\begin{array}{l}\text { Weight } \\
\text { optimization }(\mathrm{kg})\end{array}$ & 12.1 & 10.7 \\
\hline
\end{tabular}

After Check the magnitude of displacement and stress of optimized model has lower than initial model . then we have prepared pattern of new Optimized model and finally manufactured casting. Also taken test of optimized fix jaw on actual machine by applying double hydraulic pressure it has been Observed that manufactured optimized model are able sustain these load without failure so this optimized design has validated

Table 4: Total weight and cost saving

\begin{tabular}{|l|l|}
\hline Design parameter & fix jaw after optimized \\
\hline Weight reduced $(\mathrm{kg})$ & $(12.1-10.7)=1.4 \mathrm{~kg}$ \\
\hline Total cost saving/unit & $1.4 * 60=84 /-$ \\
\hline Total cost saved/year & $84 * 100=8,400 /-$ \\
\hline
\end{tabular}

\section{CONCLUSIONS}

In this project, the forces acting on fix jaw of rear vice of horizontal band saw machine has been calculated with considering factor of safety. CAD model of jaws has been carried out using Solid works software. The static analysis as well as optimization of fix jaws has been carried out in Hyperworks. Finally manufacturing casting validate on machine. From the analyzed results, it is concluded that.

- The values obtained for the maximum displacement and von mises stress of optimized model are lower than existing model.

- Topology optimization generates an optimized material distribution for a set of loads and constraints within a given design space. This Optimization reducing weight, manufacturing cost of component fulfilled with all design constraints..
-Weight optimization of rear vice resulted to $12 \%$ of weight reduction than existing model. So that company saves $8,400 /$ - per year.

-Though this work we can minimize load on resource's and help to increase productivity and increase sale machine.

\section{FUTURE SCOPE}

We can apply this weight optimization method to All casting parts of horizontal band saw machine which are over design. So we can minimize total Manufacturing cost of machine and it will better to Increase sale in market.

\section{REFERENCES}

[1]. Vinayak Kulkarni1, Anil Jadhav2, P. Basker3, "Finite Element Analysis and Topology Optimizationof Lower Arm of Double Wishbone Suspension using RADIOSS and Optistruct," International Journal of Science and Research (IJSR), Volume 3 Issue 5, May 2014.

[2]. Muni Prabaharan and V.Amarnath ,'Structural Optimization of 5Ton Hydraulic Press And Scrap Baling Press for Cost Reduction by Topology'. Published in "International Journal of Modeling and Optimization", Vol. 1, No. 3, August 2011

[3]. Vivek Zolekar, Dr. L.N. Wankhade, "Finite Element Analysis and Optimization of I.C. Engine Piston Using RADIOSS and OptiStruct", altair technology conference 2013 india.

[4]. Rinkle Garg, Sunil Baghla 'Finite Element Analysis and Optimization of Crankshaft Design', Published in "International Journal of Engineering and Management Research, Vol.-2, Issue-6, December 2012 ,ISSN No.: 22500758, Pages: 26-31.

[5]. Malleswara Swami1, K.Sunil Ratna Kumar2,"Design and structural analysis of CNC vertical milling maches", International Journal of Advanced Engineering Technology, IJAET/Vol.III/ Issue IV/Oct.-Dec. 2012/97-100

[6]. SPM tools band saw product manual.

[7]. Altair hyperworks.11 user Manual.

[8]. Pdf on SAWING MACHINES GENERAL, uhv.cheme.cmu.edu/procedures/machining/ch6.pdf

[9]. Tushar M. Patel, Dr. M. G. Bhatt, Harshad K. Patel. 'Parametric Optimization of Eicher 11.10 Chassis Frame for Weight Reduction Using FEA-DOE Hybrid Modeling', published in "International Journal of IOSR Journal of Mechanical and Civil Engineering (IOSR-JMCE)", e-ISSN: 2278-1684,p-ISSN: 2320-334X, Volume 6, Issue 2 (Mar. Apr. 2013), PP 92-100.

[10]. Waqas Saleem, Fan Yuqing, Wang Yunqiao, "Application of Topology Optimization and Manufacturing Simulations - A new trend in design of Aircraft components", Proceedings of the International Multi-Conference of Engineers and Computer Scientists 2008 Vol II IMECS 2008, 19-21 March, 2008, Hong Kong. 


\section{BIOGRAPHIES}

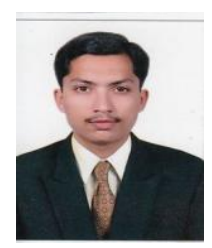

Prashant H. Patil received degrees in

Mechanical Engineering from Shivaji

University, Kolhapur.

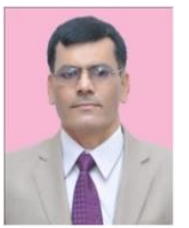

Suresh S. Patil received the B.E. and M.E.Design degrees in mechanical Engineering from Shivaji University. 